\title{
A T2 Translational Science Modified Delphi Study: Spinal Motion Restriction in a Resource-Scarce Environment
}

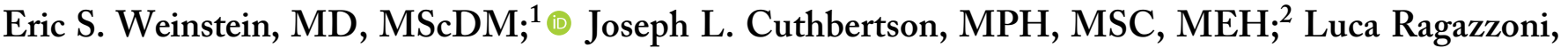 \\ $\mathrm{MD}, \mathrm{PhD}^{1}{ }^{1}$ (1) Manuela Verde, MD, MScDM ${ }^{1}$
}

1. CRIMEDIM, Università del Piemonte Orientale, Novara, Italy

2. Monash University, Disaster Resilience Initiative, Clayton, Melbourne, Victoria, Australia

\section{Correspondence:}

Eric S. Weinstein, MD, MScDM

Università del Piemonte Orientale CRIMEDIM

Research Centre in Emergency and Disaster Medicine, Novara 28100 Italy

E-mail: eswein402@gmail.com

Conflicts of interest: Manuela Verde is an employee of STAT59 Services Ltd (Edmonton, Alberta, Canada); all other authors report no conflicts of interest.

Keywords: Delphi method; resource-scarce environments; spinal injury; spinal motion restriction; Translational Science
Abbreviations:
CG: clinical guideline
C-Spine: cervical spine
DM: Disaster Medicine
MCI: mass-casualty incident
mD: modified Delphi
NEXUS: National Emergency X-Radiography
Utilization Study
RRE: resource-rich environment
RSE: resource-scarce environment
SLR: systematic literature review
SMR: spinal motion restriction
TS: Translational Science
WADEM: World Association for Disaster and
Emergency Medicine

Received: March 12, 2020

Revised: April 16, 2020

Accepted: May 6, 2020

doi:10.1017/S1049023X20000862

(c) World Association for Disaster and Emergency

Medicine 2020. This is an Open Access article,

distributed under the terms of the Creative

Commons Attribution licence (http://

creativecommons.org/licenses/by/4.0/), which permits unrestricted re-use, distribution, and reproduction in any medium, provided the original work is properly cited.

\begin{abstract}
Introduction: Emerging evidence is guiding changes in prehospital management of potential spinal injuries. The majority of settings related to current recommendations are in resource-rich environments (RREs), whereas there is a lack of guidance on the provision of spinal motion restriction (SMR) in resource-scarce environments (RSEs), such as: masscasualty incidents (MCIs); low-middle income countries; complex humanitarian emergencies; conflict zones; and prolonged transport times. The application of Translational Science (TS) in the Disaster Medicine (DM) context was used to develop this study, leading to statements that can be used in the creation of evidence-based clinical guidelines (CGs).
\end{abstract}

Objective: What is appropriate SMR in RSEs?

Methods: The first round of this modified Delphi $(\mathrm{mD})$ study was a structured focus group conducted at the World Association for Disaster and Emergency Medicine (WADEM) Congress in Brisbane Australia on May 9, 2019. The result of the focus group discussion of open-ended questions produced ten statements that were added to ten statements derived from Fischer (2018) to create the second $\mathrm{mD}$ round questionnaire.

Academic researchers and educators, operational first responders, or first receivers of patients with suspected spinal injuries were identified to be $\mathrm{mD}$ experts. Experts rated their agreement with each statement on a seven-point linear numeric scale. Consensus amongst experts was defined as a standard deviation $\leq 1.0$. Statements that were in agreement reaching consensus were included in the final report; those that were not in agreement but reached consensus were removed from further consideration. Those not reaching consensus advanced to the third $\mathrm{mD}$ round.

For subsequent rounds, experts were shown the mean response and their own response for each of the remaining statements and asked to reconsider their rating. As above, those that did not reach consensus advanced to the next round until consensus was reached for each statement.

Results: Twenty-two experts agreed to participate with 19 completing the second $\mathrm{mD}$ round and 16 completing the third $\mathrm{mD}$ round. Eleven statements reached consensus. Nine statements did not reach consensus.

Conclusions: Experts reached consensus offering 11 statements to be incorporated into the creation of SMR CGs in RSEs. The nine statements that did not reach consensus can be further studied and potentially modified to determine if these can be considered in SMR CGs in RSEs.

Weinstein ES, Cuthbertson JL, Ragazzoni L, Verde M. A T2 translational science modified delphi study: spinal motion restriction in a resource-scarce environment. Prehosp Disaster Med. 2020;35(5):538-545.

Introduction

The incidence of spinal trauma will vary depending on the specifics of the incident with a higher proportion after an earthquake, train crash, building collapse, and explosion, amongst others. ${ }^{1-3}$ The dual loyalty ${ }^{4}$ to do the most good for the most people while following standard operating procedure for the specific patient as if the patient was the only patient in typical, non-disaster trauma with similar injuries is a controversy that is thrust to the forefront with suspected spinal trauma in a disaster. Though the Canadian Cervical Spine (C-Spine) Rule $^{5}$ and the National Emergency X-Radiography Utilization Study (NEXUS) Criteria for 
C-Spine imaging, 6 have been validated and incorporated into decision algorithms in some prehospital care systems, there are systems either unconvinced or remain concerned yielding to unsubstantiated medico-legal risks and have yet to adopt the evidencebased decision process to provide spinal protection in any scenario. Even the nomenclature of "spinal immobilization" has been slow to fade, despite physiologic and other studies proving that the spine is not immobilized despite implementation of commercial and creative materials and techniques. ${ }^{8-10}$

Hadley and Walters discuss the difficulties developing an evidence-based medicine approach in the management of potential cervical spine injuries in 2019 from a neurosurgical perspective, finding a lack of evidence to support and inform practice. ${ }^{11}$ Applying Translational Science (TS $)^{12,13}$ in Disaster Medicine (DM) is the solution to the challenges mentioned by StraussRiggs $^{14}$ of limited high-quality data and extreme urgency to improve outcomes using evidence-based medicine. This is paramount when acknowledging the lack of appropriate spinal protection where conventional spinal protection materials for those trained are limited or unavailable, and concerns for those untrained that are the first responders in resource-scarce environments (RSEs), including: mass-casualty incident (MCI); in a low-middle income country, complex humanitarian emergency, or conflict zone; or with prolonged transport times. The question "Does the evidence-based science that a spinal protection algorithm ${ }^{15}$ that has been shown to be clinically effective in the civilian resource-rich environments (RREs) apply to the RSE?" is the TS stage T0 pursuit. ${ }^{16}$ The T1 proof of concept study in DM is a Preferred Reporting Items for Systematic Reviews and Meta-Analyses (PRISMA) Systematic Literature Review (SLR) that demonstrates the lack of evidence-based clinical guidelines (CGs) that are applicable in RSE. ${ }^{17}$

The translation to patients, TS stage T2, is difficult in DM without (the impractical and unattainable) phase-two and phasethree clinical trials. Instead, the creation of CGs remains the typical approach in DM developed through consensus where experts gather and discuss a topic. Usually, the professional associations or academic centers that are represented by these experts then support these consensus CGs, en masse. The Delphi Method is preferred as the scientific process to reach agreement amongst a group of experts on a certain issue where none previously existed to achieve the highest level of science. ${ }^{18} \mathrm{~A}$ modified Delphi $(\mathrm{mD})$ involves any variation of settings to include on-line as this study. This study follows the recommendation of Koenig ${ }^{19}$ to achieve the goal of public health and disaster research to create new knowledge and transfer evidence-based data to improve public health. The objective is to show that experts can reach consensus to create spinal motion restriction (SMR) guidelines in RSEs using a scientific method (Table 1).

\section{Methods}

The first $\mathrm{mD}$ round was a workshop at the World Association for Disaster and Emergency Medicine (WADEM; Madison, Wisconsin USA) Congress in Brisbane Australia on May 9, 2019 attended by those interested in the initial treatment of spinal trauma in RSE (Table 2). Two authors (JC and LR) asked the group a series of open-ended questions with the answers recorded. Ten statements were derived from these open-ended questions, and an additional ten statements were derived from Fischer. ${ }^{20}$

\begin{tabular}{|l|l|}
\hline T0 & $\begin{array}{l}\text { SMR in RSE: MCI, LMIC, CHE, CZ, Prolonged Transport } \\
\text { Time }\end{array}$ \\
\hline T1 & $\begin{array}{l}\text { Potential for Intervention: Systematic Literature Review SMR } \\
\text { in RSE }\end{array}$ \\
\hline T2 & $\begin{array}{l}\text { Clinical Application: Evidence-Based Guidelines through mD } \\
\text { Method }\end{array}$ \\
\hline T3 & $\begin{array}{l}\text { Implementation: Live Exercise, Computer Simulation, } \\
\text { Blended }\end{array}$ \\
\hline T4 & $\begin{array}{l}\text { Effects on Practice: Prospective in MCl, LMIC, CHE, CZ, } \\
\text { Prolonged Transport }\end{array}$ \\
\hline
\end{tabular}

Table 1. Translational Science Phases of SMR in RSE Abbreviations: CHE, complex humanitarian emergency; CZ, conflict zone; LMIC, low-middle income country; MCI, mass-casualty incident; $\mathrm{mD}$, modified Delphi; RSE, resource-scarce environment; $\mathrm{SMR}$, spinal motion restriction.

\begin{tabular}{|c|c|}
\hline$N=18$ & Profession $^{a}$ \\
\hline 5 & Emergency Physician \\
\hline 1 & Physician \\
\hline 1 & Intensive Care Unit Physician \\
\hline 2 & Nurse \\
\hline 2 & Paramedic \\
\hline 3 & General Practitioner \\
\hline 1 & Trauma Surgeon \\
\hline 2 & Not Stated \\
\hline
\end{tabular}

Table 2. Brisbane Congress Focus Group mD-1 Participant Demographics

Abbreviation: $\mathrm{mD}$, modified Delphi.

a Self-identified at workshop sign-in.

Administration and analysis of the study was performed using Stat59 (STAT59 Services Ltd; Edmonton, Alberta, Canada).

Academic researchers, operational first responders, or first receivers of patients with suspected spinal trauma were identified from the SLR, ${ }^{17}$ with additional research of studies or operational publications to act as experts. An introductory email was sent to solicit interest with a follow-up phone or videoconference to answer any questions or to explain the study if requested by an expert.

Experts that agreed were sent an email with a link to the STAT59 website consent page. Each expert registered with their self-selected username and password, then after a validation process, each were sent an email to log back onto their secure webpage to begin the second round of the $\mathrm{mD}$ study: the first expert round. The expert received a formal explanation of the $\mathrm{mD}$, understanding the process and their anonymity, with a link to the STAT59 security measures, and then the first expert questionnaire: twenty (20) statements that were created in the first $\mathrm{mD}$ round with instruction to rank each statement on a seven-point linear numeric scale and six (6) demographic questions. Consensus amongst experts was defined as a standard deviation $\leq 1.0$.

Statements that were in agreement reaching consensus after this first expert round were included in the final report; those that were not in agreement but reached consensus would be removed from 


\begin{tabular}{|l|l|c|c|c|}
\hline & \multicolumn{1}{|c|}{ Question } & Yes & No & NA \\
\hline 1 & $\begin{array}{l}\text { Have you attended patients in an RSE } \\
\text { with actual or potential spinal trauma? } \\
\text { N=18 }\end{array}$ & 16 & 2 & 1 \\
\hline 2 & $\begin{array}{l}\text { Are you or have you been Advanced } \\
\text { Trauma Life Support certified? N=19 }\end{array}$ & 12 & 6 & $1^{\text {a }}$ \\
\hline 3 & $\begin{array}{l}\text { Have you published an article in a peer- } \\
\text { review journal or academic textbook on } \\
\text { the subject of triage and/or treatment of } \\
\text { spinal trauma? N=18 }\end{array}$ & 9 & 8 & 2 \\
\hline
\end{tabular}

Table 3. Expert Demographics

Abbreviation: RSE, resource-scarce environment.

${ }^{a}$ Trauma Nursing Core Course.

further consideration. Those not reaching consensus advanced to the second expert round. For this second expert round (and subsequent rounds if required), each expert was asked to log back onto their individual STAT59 website page for that round, showing the mean response of the experts for that specific remaining statement and their own response for that specific remaining statement, and asked to reconsider their seven-point linear numeric scale. The final report lists all statements reaching consensus ordered by strength of agreement. These statements will be offered to formulate SMR guidelines in RSE based on this scientific study.

The McLeod Health Institutional Review Board Office (Florence, South Carolina USA) has determined that this study does meet the exemption criteria found at 45 CFR 46.104(d)(2). ${ }^{21}$

\section{Results}

Experts were identified and were sent an introductory email by the principal investigator (EW) with an invitation to join the expert panel, and if they desired, to arrange a conference to further explain the $\mathrm{mD}$ process. Twenty-two confirmed their participation in the first expert round by return email and established a unique account on the STAT59 website. Nineteen completed the first round that was open from September 29, 2019 to October 19, 2019 (Table 3 and Table 4). Four statements reached statistical significance with a standard deviation less than or equal to $1.0(\leq 1.0)$ after the first expert round, achieving consensus, and were removed from further consideration.

On October 21, 2019, the 19 experts that completed the first expert round received an email announcing the opening of the second expert round. Sixteen completed the second round that was open from October 21, 2019 to November 11, 2019. Seven more statements achieved consensus after the second expert round (Table 5). The remaining nine statements were unable to reach consensus remaining with a standard deviation greater than 1.0 (>1.0; Table 6).

\section{Discussion}

The concept of spinal immobilization has been proven to be a misnomer, as the spine is not immobilized. Years of precise instruction based on assumptions have been appropriately challenged by scientific examination. ${ }^{22-25}$ Regardless, this concept has been reinforced at all levels of prehospital and hospital provider education that has led to expected spinal immobilization practice competencies. ${ }^{26}$ Unfortunately, the medico-legal application of standard of care has only further promulgated the doctrine, despite widely accepted studies demonstrating the contrary in most clinical scenarios. ${ }^{27}$
Manufacturers have capitalized to meet the need to provide state of the art devices that are designed to adhere to provider's specifications. $^{28}$ Despite the introduction of the leading Canadian C-Spine rules and the NEXUS study, prehospital private and public response agencies have followed their medical control physician's direction, in part due to State Department of Health Emergency Medical System or other similar regulatory agency's requirements. First receiving physicians in emergency departments have gradually accepted the growing science, but were slow to advocate in most jurisdictions, working around the misapplication of an ever-increasing sophisticated immobilization apparatus with rapid removal of the disposable materials. Though some prehospital agencies have adapted and adjusted their standard operating procedures to follow the science, others have not, or have been reticent based on the imminent threat of perceived litigation in certain jurisdictions. Professional associations through the years have supported the science and were not successful to achieve widespread acceptance. $^{29}$

The RREs with the highest level of trained first responders, replete with spinal immobilization supplies, have maintained the practice of spinal immobilization with the majority of patients fully expecting to be placed in a rigid cervical collar, strapped to a long board for transport to the emergency department, on occasion enduring lengthy periods uncomfortably flat, as this was what they were told was best for them, ${ }^{30}$ not only by the providers, but images on screens and billboards small and large. But what of the prehospital and hospital providers that practice in low- or middle-income countries, complex humanitarian emergencies, or conflict zones? Keen to match limited resources with exceeding patient demand, while at times in unstable environments, they were not encumbered by their decisions to disregard their expected practice of spinal immobilization even before the science met their attention to the dual loyalty of an MCI. ${ }^{31}$ One can argue that altered standard of care is an accepted means to allocate limited resources in an MCI. Certainly, no one can support treatment of an injured spine with measures that would further injure the spine. If the standard is to convince a walking patient that it would be in their best interest to have a cervical collar (often mis-) ${ }^{32,33}$ applied, packaged on a board, then why is this typically not expected when the number of patients exceeds the supply of ready-made disposable materials and boards made of increasingly lighter materials that have evolved to not interfere with $\mathrm{x}$-rays? Joining these providers in RSEs are those that have long transport times that can attest to the countless patients that were made worse after emesis (that later developed aspiration pneumonia), or their myofascial strain that was compounded by the limited ability to move for extended periods. ${ }^{34,35}$

Members of WADEM called for a round-table discussion at the biannual WADEM Congress in Toronto in May 2017 to discuss the continued lack of acceptance of science in RREs hindering the triage and treatment of patients injured in a RSE with potential spinal injuries. ${ }^{27} \mathrm{~A}$ author of this study (JC) lead this round table discussion, with over 50 interested participants from all professional levels of training and experiences from the full breadth of RSEs. This concluded with the attendees asking the WADEM Board of Directors (Board) to produce a "white paper" to address the triage and treatment of the patient with potential spinal injuries in an RSE or with prolonged transport times. Shortly thereafter, the Board appointed two members (JC and EW, who transcribed 


\begin{tabular}{|c|c|c|}
\hline \multirow[t]{2}{*}{4} & \multicolumn{2}{|c|}{ Have you attended spinal trauma patients in the past or currently as: (select all that apply) $N=19$} \\
\hline & $\begin{array}{l}\text { a) Anesthesia/Critical Care } \\
\text { b) Emergency Medicine Physician } \\
\text { c) EMT/Paramedic } \\
\text { d) Fire/Rescue } \\
\text { e) Nurse } \\
\text { f) Physiatrist } \\
\text { g) Search and Rescue (Land or Helicopter) } \\
\text { h) Spinal Surgeon (Orthopedic) } \\
\text { i) Spinal Surgeon (Neurosurgeon) } \\
\text { j) Trauma Surgeon } \\
\text { k) Other }\end{array}$ & $\begin{array}{l}0 \\
8 \\
2 \\
1 \\
1 \\
2 \\
2 \\
2 \\
1 \\
3 \\
2^{\mathrm{a}}\end{array}$ \\
\hline \multirow[t]{2}{*}{5} & \multicolumn{2}{|c|}{ Have you performed spinal trauma research in the past or currently as: (select all that apply) $N=16$} \\
\hline & $\begin{array}{l}\text { a) Anesthesia/Critical Care } \\
\text { b) Emergency Medicine Physician } \\
\text { c) EMT/Paramedic } \\
\text { d) Fire/Rescue } \\
\text { e) Nurse } \\
\text { f) Physiatrist } \\
\text { g) Search and Rescue (Land or Helicopter) } \\
\text { h) Spinal Surgeon (Orthopedic) } \\
\text { i) Spinal Surgeon (Neurosurgeon) } \\
\text { j) Trauma Surgeon } \\
\text { k) Other } \\
\text { l) None }\end{array}$ & $\begin{array}{l}0 \\
4 \\
0 \\
0 \\
0 \\
2 \\
0 \\
1 \\
1 \\
1 \\
2 \\
8 \\
\end{array}$ \\
\hline \multirow[t]{2}{*}{6} & \multicolumn{2}{|c|}{$\begin{array}{l}\text { Have you instructed triage and/or treatment of spinal trauma patients in the past or currently as: (select all } \\
\text { that apply) } \mathrm{N}=19\end{array}$} \\
\hline & $\begin{array}{l}\text { a) Anesthesia/Critical Care } \\
\text { b) Emergency Medicine Physician } \\
\text { c) EMT/Paramedic } \\
\text { d) Fire/Rescue } \\
\text { e) Nurse } \\
\text { f) Physiatrist } \\
\text { g) Search and Rescue (Land or Helicopter) } \\
\text { h) Spinal Surgeon (Orthopedic) } \\
\text { i) Spinal Surgeon (Neurosurgeon) } \\
\text { j) Trauma Surgeon } \\
\text { k) Other } \\
\text { l) None }\end{array}$ & $\begin{array}{l}0 \\
7 \\
2 \\
0 \\
1 \\
2 \\
1 \\
2 \\
1 \\
1 \\
3^{1} \\
2\end{array}$ \\
\hline
\end{tabular}

Table 4. Expert Demographics: Per Specialty Abbreviation: EMT, emergency medical technician. a Trauma Case Manager.

the workshop proceedings) to commence work with the expectation to deliver a "white paper," or similar series of recommendations to be discussed and then approved by the Board to be widely distributed. Encouraged by the support of the Board, the decision was made to apply this round-table discussion to a TS process following Koenig's call to action published in October $2017 .{ }^{19}$ The goals were to move past paper to devote time and effort to the lengthy process to impact clinical practice.

Translation Science has become the accepted process for new pharmaceuticals, techniques, or technology to adapt or replace current clinical practice. Disaster Medicine has inherent difficulties applying the process of turning observations in the laboratory into interventions that improve the health of individuals and the public using diagnostics and therapeutics to medical procedures. However, the DM lab can be considered a tabletop, computer simulation, live-, or blended-exercise. By definition, DM procedures come from the disaster cycle: mitigation to include risk reduction, preparation to include education and training, response with standard operating procedures, and recovery. The phases of TS can be applied to DM by first stating lessons learned from an after-action report, or in this instance, from a round-table discussion:
- T0: Identification of opportunities and approaches to a health problem $=$ triage and treatment of potential spinal injuries in an RSE;

- T1: Basic research for clinical effect and/or applicability, human physiology knowledge, and potential for intervention = SLR;

- T2: New interventions to form basis for clinical application and evidence-based guidelines = the Delphi Method;

- T3: Implementation of research findings in clinical practice $=$ the creation of evidence-based CGs with education, training, and competencies; and

- T4: Effects on practice influencing populations and policy = study of the competencies and CGs outcomes.

Consensus CGs are the lowest strength of evidence created, adopted, and promulgated by professional associations, academic, and research centers, and endorsed by government, regulatory, and other supervisory bodies finding their rightful place in medical practice. The opinion-based process to create CGs is shifting to processes that are evidence-informed, including increasingly sophisticated methodologies and implementation strategies. $^{36}$ 


\begin{tabular}{|c|c|c|c|c|c|}
\hline & Statements Attaining Consensus & Mean & SD & $\begin{array}{l}\text { Consensus } \\
\text { Round }\end{array}$ & Expert $n$ \\
\hline 1 & $\begin{array}{l}\text { The risk of aspiration and soft tissue pressure injuries has to be considered } \\
\text { when utilizing SMR in an RSE with prolonged waiting and transportation } \\
\text { times. }{ }^{\text {a }}\end{array}$ & 6.6 & 0.8 & 2 & 16 \\
\hline 2 & $\begin{array}{l}\text { Protocols should be developed for patients that receive SMR in RSE to be } \\
\text { attentive to the risk of aspiration and soft tissue injury. }^{\text {a }}\end{array}$ & 6.5 & 0.9 & 1 & 19 \\
\hline 3 & $\begin{array}{l}\text { Protocols should be developed at alternate medical posts, casualty } \\
\text { collection sites, and definitive care to reassess the patent in SMR for prompt } \\
\text { removal of the SMR when appropriate. }\end{array}$ & 6.4 & 0.5 & 2 & 16 \\
\hline 4 & $\begin{array}{l}\text { Movement of the patient with SMR from one surface to another requires } \\
\text { teamwork and attention to maintaining the SMR. }{ }^{\mathrm{b}}\end{array}$ & 6.4 & 0.9 & 1 & 19 \\
\hline 5 & $\begin{array}{l}\text { SMR should replace SI as the process to minimize unwanted movement of } \\
\text { a potentially injured spine. }\end{array}$ & 6.2 & 0.8 & 1 & 19 \\
\hline 6 & $\begin{array}{l}\text { The resources for SMR for extrication in an unstable environment may } \\
\text { require utilization of unconventional materials to not jeopardize rescuers } \\
\text { and the patient. }^{\text {a }}\end{array}$ & 6.2 & 0.8 & 2 & 16 \\
\hline 8 & $\begin{array}{l}\text { Distracting injuries or lack of reliable physical examination in an RSE should } \\
\text { not be the sole reasons to perform SMR. }\end{array}$ & 5.9 & 0.8 & 2 & 16 \\
\hline 9 & $\begin{array}{l}\text { Limiting C-spine movement is the critical goal of SMR in an RSE using } \\
\text { available resources in concert with maintenance of head, neck, and torso } \\
\text { alignment. }\end{array}$ & 5.8 & 1.0 & 2 & 16 \\
\hline 10 & $\begin{array}{l}\text { Simplified SMR utilizing available resources in an RSE can be explained } \\
\text { just-in-time to expedite extrication and transportation to appropriate next } \\
\text { level care. }{ }^{\text {a }}\end{array}$ & 5.6 & 0.8 & 1 & 19 \\
\hline 11 & $\begin{array}{l}\text { SMR should be utilized when prior SI, central or peripheral nervous system, } \\
\text { or other abnormalities cannot be determined with adaptation of the SMR. }\end{array}$ & 4.9 & 1.0 & 2 & 16 \\
\hline
\end{tabular}

Table 5. Statements Attaining Consensus

Abbreviations: C-spine, cervical spine; NEXUS, National Emergency X-Radiography Utilization Study; RSE, resource-scarce environment; SI, spinal immobilization; SMR, spinal motion restriction.

${ }^{a}$ Derived from the modified Delphi Focus Group.

${ }^{\mathrm{b}}$ Derived from Fisher.

The Delphi Method has grown since inception to forecast the impact of technology in warfare in the 1950s to make the best of a less than perfect fund of knowledge, or where none existed previously. Keeney cautions that the Delphi Method is not to replace rigorous scientific reviews of published reports or original research. ${ }^{37}$ The Delphi Method can overcome consensus expert panel members:

- Dynamic personalities or positions of authority that command acquiescence of other panel members due to competing interests or partisanship;

- Presenting with an agenda contrary to or diverting from the tasks of the consensus panel; and

- Lack of diversity of factual opinion.

The first round of a $\mathrm{mD}$ method study obtains guidance from a focus group to establish the statements for presentation to an expert panel to achieve consensus. In Brisbane in May 2019 at the WADEM Congress, a second workshop discussed the triage and treatment of potential spinal injury patients in an RSE or with prolonged transport times. This was open to any interested attendee, led by an author (JC), with another author (LR) providing further direction. Information obtained from the SLR was used to create open-ended questions posed to the assembled to create ten statements for the planned $\mathrm{mD}$ study to follow. The attendees were not informed of their role as a focus group to create Delphi statements, nor were the Fischer ${ }^{20} \mathrm{CG}$ s discussed to avoid any bias in the creation of the statements. The Fischer ${ }^{20} \mathrm{CG}$ were used to create the remaining ten statements of the Delphi study, supported by the respective professional associations of the participants.

The Delphi expert panel members seek consensus with agreement or disagreement amongst themselves. Internal validity is largely unknown; therefore, stability of response is more accurate to determine agreement or disagreement. Despite a lack of a standardized Delphi process, this study sought to accomplish the majority of published accepted Delphi methodology: ${ }^{18,37-42}$

- A SLR was completed;

- Background information: the SLR findings were provided to participants;

- Ranking system: seven-point linear numeric scale;

- The number of participants/round: goal $\geq 12$ achieved;

- Polling was conducted via email;

- Private decisions were collected: anonymity;

- Formal feedback of group ratings was shared at expert round two;

- Number of rounds $\geq$ two until stability; and

- Consensus a priori with a standard deviation $\leq 1.0$. 


\begin{tabular}{|c|c|}
\hline & Statements Not Attaining Consensus \\
\hline 1 & $\begin{array}{l}\text { Validated clinical decision rules such as the Canadian } \\
\text { C-Spine and NEXUS should be incorporated into the decision } \\
\text { to utilize SMR in RSE. }{ }^{\text {a }}\end{array}$ \\
\hline 2 & $\begin{array}{l}\text { There is no role for SMR in penetrating, non-blast (gunshot, } \\
\text { stab) trauma. }\end{array}$ \\
\hline 3 & $\begin{array}{l}\text { Rapid extrication and transport to appropriate next level care } \\
\text { to "Stop the Bleeding" takes priority over adherence to a } \\
\text { lengthy SMR process. }\end{array}$ \\
\hline 4 & $\begin{array}{l}\text { Triage, scene treatment, and transportation of a patient with } \\
\text { suspected spinal injury in an RSE has to be balanced with } \\
\text { competing available resources and potential subsequent care } \\
\text { of other patients involved. }{ }^{\text {a }}\end{array}$ \\
\hline 5 & $\begin{array}{l}\text { After extrication in an RSE, SMR elements can be removed } \\
\text { for comfort of that patient while maintaining SMR with } \\
\text { expected prolonged transportation to utilize these elements } \\
\text { for other patients. }\end{array}$ \\
\hline 6 & $\begin{array}{l}\text { Minimal documentation of time in SMR should accompany the } \\
\text { patient from the scene to definitive care. }{ }^{\text {a }}\end{array}$ \\
\hline 7 & $\begin{array}{l}\text { First responders in an RSE can develop reasonable SMR } \\
\text { strategies with inexpensive readily available materials. }{ }^{a}\end{array}$ \\
\hline 8 & $\begin{array}{l}\text { There is no evidence supporting a high-risk/incidence of } \\
\text { non-contiguous multi-level spinal injury in children. }\end{array}$ \\
\hline 9 & $\begin{array}{l}\text { Appropriate utilization of available resources in an RSE that } \\
\text { approximates a cervical collar, if the correct cervical collar is } \\
\text { not available, should be applied to a child if any: }{ }^{\text {b }} \\
\text { a. Complaint of Neck Pain } \\
\text { b. Torticollis or Cervical Spasm } \\
\text { c. Neurologic Deficit (new or of unknown duration) } \\
\text { d. Altered Mental Status for Age } \\
\text { e. High-Energy Motor Vehicle (2- or 4-wheel) Crash, Diving, } \\
\text { or Major Torso Injury }\end{array}$ \\
\hline
\end{tabular}

Table 6. Statements Not Attaining Consensus

Abbreviations: C-spine, cervical spine; NEXUS, National Emergency $\mathrm{X}$-Radiography Utilization Study; RSE, resource-scarce environment; SMR, spinal motion restriction.

${ }^{a}$ Others derived from the modified Delphi Focus Group.

${ }^{\mathrm{b}}$ Derived from Fisher.

This study's expert panel has attended patients, performed academic research, or were educators providing instruction of patients with suspected spinal injuries in RSEs or with prolonged transport times. A major distinction between the expert of a typical consensus panel CG and an anonymous Delphi expert is the faith that these experts are indeed appropriate to participate. It must be accepted that in the end, the Delphi Method remains the opinion of assembled expert panel members.

This study reached consensus to replace "spinal immobilization" with SMR to more accurately reflect the mechanical treatment process. With time and continued research, this nomenclature may eventually become more widespread to become universally accepted. Statements attaining consensus concerning the risk of aspiration and soft tissue pressure injuries ${ }^{43}$ when utilizing SMR in the RSE and the development of protocols to be attentive to these risks balances the risk/benefit following published studies. If a patient requires extrication from the scene to be delivered to a casualty collection point, there is consensus to re-evaluate the patient to remove the SMR utilized for the extrication. Furthermore, consensus supported a prudent team approach to move the patient from one surface to another, as would occur in an RRE.

The creative use of SMR materials in an RSE has previously been reported in response to earthquake ${ }^{44}$ events and has most likely occurred or will occur in other MCIs and RSEs. This study reached consensus to support this approach to not jeopardize responders and patients. The consensus to utilize SMR when there is definitive spinal injury, pre-existing, or unknown peripheral or central nervous system conditions remains in this study. These statements will spur those who develop CGs to develop parameters based on the above risk/benefits, as well as the use of available capable materials.

The practice of "defensive SMR" out of unsubstantiated fear of medico-legal exposure does not adhere to the validated Canadian C-Spine and NEXUS rules. ${ }^{27}$ The development of CGs are encouraged to include the development of just-in-time training that would be directed to the assembled unsolicited volunteers to address preconceived notions not based on the available science. The principle of "Primum non nocere" (do no harm) can be taught to immediate and first responders, as well as these volunteers, to assure that restricting spinal motion utilizing available resources in the context of the scenario is to expedite safe extrication and transportation to the next level of care.

The statement that validated clinical decision rules such as the Canadian C-Spine and NEXUS should be incorporated into the decision to utilize SMR in RSEs did not reach consensus, despite other statements that were based on these rules reaching consensus cannot be easily explained. There have been numerous studies that have shown that there is no role for SMR in penetrating, non-blast (gunshot, stab) trauma. ${ }^{45-47}$ This statement did not reach consensus, perhaps due to a lack of exposure to these injuries in the practice of a few experts. During the creation of the CGs, education and exercise TS T3 phase the scientific evidence will be discussed and developed in detail.

"Stop the bleeding" with application of direct pressure, tourniquets, and rapid transport to definitive care has become a standard goal of blunt and penetrating trauma patients. The application of this approach would be reasonable to take priority over a lengthy SMR process. ${ }^{45}$ However, the experts did not reach consensus without an explanation; though similar to penetrating trauma, this may not be in the practice of certain experts and can be remedied during the CGs creation, education, and exercise T3 phase. The lack of consensus to remove SMR when faced with prolonged transport and that first responders can develop reasonable SMR strategies with inexpensive readily available materials may require more detailed CGs with dedicated education and exercises.

Accurate recording of the time that the patient has been in SMR is necessary to best determine the risk of soft tissue pressure injuries, ${ }^{35}$ but this statement did not reach consensus. Similarly, CGs that require rudimentary triage and treatment times of patients that are injured in RSEs should include application of SMR to become standard, as if the patient was in an RRE.

The lack of consensus regarding balancing the needs of a patient with suspected spinal injuries with competing available resources and subsequent care of other patients demonstrates the difficulty satisfying the dual loyalty in an MCI.

Fischer ${ }^{20}$ wrote that there is no evidence supporting a high-risk/ incidence of non-contiguous multi-level spinal injury in children. This did not reach consensus by the study panel of experts without an explanation other than the panel was not aware of these data. The statement that appropriate utilization of available resources in an RSE that approximates a cervical collar, if the correct cervical collar is not available, should be applied to a child was derived from Fischer ${ }^{20}$ and did not reach consensus. In an RRE, despite available pre-made materials, improvisation is an important 
distinct approach to SMR an injured child with suspected spinal injuries, and this would be expected in an RSE. This would be another area that the TS T3 creation of CGs, education, and exercise phase can address.

\section{Limitations}

The distribution of experts was designed to represent medical specialties that would attend, study, or instruct the care of an injured patient with suspected spinal injuries, except that no anesthesia/ critical care specialist joined the panel. In some countries without paramedics in their Emergency Medical System, this physician would be the first responder, and their opinion might have changed the end result.

Since the study is anonymous, the statistician (JF) by design was unable to identify the three experts of the 22 that agreed to participate, but did not complete the first expert round questionnaire with demographic questions. If any number of these three experts had joined the panel, results may have changed.

Three experts of the 19 that completed the first expert round did not complete the second expert round questionnaire. One expert did contact the principal investigator (EW), as they were unable to overcome their workplace's firewall and they were unable to continue from expert round one to expert round two despite efforts of the STAT59 team. Since the study is anonymous, the statistician by design was unable to identify the other two experts that dropped out between rounds. It is unknown if any one of these experts would have influenced the end results.

There are inherent limitations of a Delphi study, specifically a lack of standardized process. This study followed the recommendations or guidelines of six Delphi methodology publications.

\section{Conclusion}

The Delphi Method uses a scientific process to analyze the opinions of individuals from varied backgrounds to achieve agreement where none existed previously. There is no standard or accepted expert selection process, number of experts, or expert rounds for a Delphi process study. This study met Delphi Method health care study design parameters. Anonymity eliminated the undue dominance by individuals ${ }^{41}$ in the usual health care consensus panel process. Experts reached consensus offering 11 statements to be incorporated into the creation of local, regional, or national SMR CGs in RSEs. The statements that did not reach consensus can be further studied to determine if these can be modified to be considered in SMR CGs in RSEs. The next TS phase will be to study the efficacy of education of these CGs, as well clinical outcome research, after the CGs have been incorporated into prehospital care in RSEs.

\section{Acknowledgement}

Thanks to Jessica Weinberg for her insight and direction.

\section{References}

1. Gautschi OP, Cadosch D, Rajan G, Zellweger R. Earthquakes and trauma: review of triage and injury-specific, immediate care. Prehosp Disaster Med. 2008;23(2):195-201.

2. Lodhi A, Khan SA, Ahmed E, et al. Prehospital management of spinal injuries in a natural disaster. J Ayub Med Coll Abbottabad. 2011;23(4):10-12.

3. Priebe MM. Spinal cord injuries as a result of earthquakes: lessons from Iran and Pakistan. J Spinal Cord Med. 2007;30(4):367-368.

4. Karadag OC, Hakan AK. Ethical dilemmas in disaster medicine. Iran Red Crescent Med J. 2012;14(10):602-612.

5. Stiell IG, Wells GA, Vandemheen KL, et al. The Canadian C-Spine rule for radiography in alert and stable trauma patients. JAMA. 2001;286(15):1841-1848.

6. Stiell IG, Clement CM, McKnight RD, et al. The Canadian C-Spine rule versus the NEXUS low-risk criteria in patients with trauma. N Engl J Med. 2003;349(26): 2510-2518.

7. Hoffman JR, Mower WR, Wolfson AB, Todd KH, Zucker MI. Validity of a set of clinical criteria to rule out injury to the cervical spine in patients with blunt trauma. National Emergency X-Radiography Utilization Study Group. $N$ Engl J Med. 2000;343(2):94-99.

8. Morrissey JF, Kusel ER, Sporer KA. Spinal motion restriction: an educational and implementation program to redefine prehospital spinal assessment and care. Prehosp Emerg Care. 2014;18(3):429-432.

9. Hawkins S, Williams J, Bennett B, Islas A, Kayser DW, Quinn R. Wilderness Medical Society clinical practice guidelines for spinal cord protection. Wilderness Environ Med. 2019;30(4S):S87-S99.

10. Bednar DA. Efficacy of orthotic immobilization of the unstable subaxial cervical spine of the elderly patient: investigation in a cadaver model. Can J Surg. 2004;47(4):251256.

11. Hadley MN, Walters BC. The case for the future role of evidence-based medicine in the management of cervical spine injuries, with or without fractures. J Neurosurg Spine. 2019;31(4):457-463.

12. Tufts Clinical Science and Translational Institute. What is Translational Science? https://www.tuftsctsi.org/about-us/what-is-translational-science/. Accessed August $18,2019$.

13. National Center for Advancing Translational Sciences. Translational Science Spectrum 2015. https://ncats.nih.gov/files/translation-factsheet.pdf. Accessed August 18, 2019.

14. Strauss-Riggs K, Yeskey K, Miller A, Arnesen S, Goolsby C. Translating battlefield practices to disaster health. Disaster Med Public Health Prep. 2017;11(4):510-511.

15. NC OEMS. Selective Spinal Motion Restriction 2015. https://www.ncems.org/ nccepstandards/protocols/90SelectiveSpinalImmobilization.pdf. Accessed August $18,2019$.
16. National Association of EMS Physicians and the American College of Surgeons Committee on Trauma. EMS Spinal Precautions and the Use of the Long Backboard 2012. https://www.facs.org/ /media/files/quality programs/trauma/vrc resources/9_backboardpositionpaper final approved_2012.ashx). Accessed August 18, 2019.

17. Cuthbertson J, Weinstein ES. Spinal immobilization in disasters: a systematic review. Prehosp Disaster Med. 2020;35(4).

18. Hasson F, Keeney S, McKenna H. Research guidelines for the Delphi survey technique. J Adv Nurs. 2000;32(4):1008-1015.

19. Koenig KL, Schultz CH, Runnerstrom MG, Ogunseitan OA. Public health and disasters: an emerging translational and implementation science, not "lessons learned." Disaster Med Public Health Prep. 2017;11(5):610-611.

20. Fischer PE, Perina DG, Delbridge TR, et al. Spinal motion restriction in the trauma patient - a joint position statement. Prehosp Emerg Care. 2018;22(6):659-661.

21. United States Department of Health and Human Services. Part 46-Protection of Human Subjects. Subpart A- Basic HHS Policy for Protection of Human Research Subjects. \$46.104 Exempt research. https:/www.ecfr.gov/CGsi-bin/retrieveECFR? $\mathrm{gp}=\& \mathrm{SID}=83 \mathrm{~cd} 09 \mathrm{e} 1 \mathrm{c} 0 \mathrm{f5} 6 \mathrm{c} 637 \mathrm{~cd} 9 \mathrm{~d} 7513160 \mathrm{fc} 3 \mathrm{f} \& \mathrm{pitd}=20180719 \& \mathrm{cn}=\mathrm{pt} 45.1$ 46\&r=PART\&ty=HTML - se45.1.46_1104. Accessed August 18, 2019.

22. Kwan I, Bunn F. Effects of prehospital spinal immobilization: a systematic review of randomized trials on healthy subjects. Prehosp Disaster Med. 2005;20(1):47-53.

23. Liao S, Schneider NRE, Huttlin P, et al. Motion and Dural sac compression in the upper cervical spine during the application of a cervical collar in case of unstable craniocervical junction - a study in two new cadaveric trauma models. PLoS One. 2018;13(4):e0195215.

24. Swartz EE, Tucker WS, Nowak M, et al. Prehospital cervical spine motion: immobilization versus spine motion restriction. Prehosp Emerg Care. 2018;22(5):630-636.

25. Pryce R, McDonald N. Prehospital spinal immobilization: effect of effort on kinematics of voluntary head-neck motion assessed using accelerometry. Prehosp Disaster Med. 2016;31(1):36-42.

26. Ireland CJ, Zeitz KM, Bridgewater FHG. Acquiring and maintaining competence in the application of extrication cervical collars by a group of first responders. Prehosp Disaster Med. 2008;23(6):530-536.

27. Sundstrøm T, Asbjørnsen H, Habiba S, Sunde GA, Wester K. Prehospital use of cervical collars in trauma patients: a critical review. J Neurotrauma. 2014;31(6):531-540.

28. Rahmatalla S, DeShaw J, Stilley J, Denning G, Jennissen C. Comparing the efficacy of methods for immobilizing the cervical spine. Spine. 2018;44(1):32-40.

29. White IV C, Domeier RM, Millin MG; Standards and Clinical Practice Committee NAoEP. EMS spinal precautions and the use of the long backboard -resource document to the Position Statement of the National Association of EMS Physicians and the 
American College of Surgeons Committee on Trauma. Prehosp Emerg Care. 2014;18(2):306-314.

30. Ottosen CI, Steinmetz J, Larsen MH, Baekgaard JS, Rasmussen LS. Patient experience of spinal immobilization after trauma. Scand J Trauma Resusc Emerg Med. 2019;27(1):70.

31. Hauswald M, Ong G, Tandberg D, Omar Z. Out-of-hospital spinal immobilization: its effect on neurologic injury. Acad Emerg Med. 1998;5(3):214-219.

32. Kreinest M, Goller S, Rauch G, et al. Application of cervical collars - an analysis of practical skills of professional emergency medical care providers. PLoS One. 2015;10(11):e0143409.

33. Ahmed OZ, Webman RB, Shetha PD, et al. Errors in cervical spine immobilization during pediatric trauma evaluation. J Surg Res. 2018;228:135-141.

34. Clemency BM, Tanski CT, Chambers JG, et al. Compulsory use of the backboard is associated with increased frequency of thoracolumbar imaging. Prehosp Emerg Care. 2018;22(4):506-510.

35. Theodore N, Hadley MN, Aarabi B, et al. Prehospital cervical spinal immobilization after trauma. Neurosurgery. 2013;72(Suppl 2):22-34.

36. Kredo T, Bernhardsson S, Machinghaidze S, et al. Guide to clinical practice guidelines: the current state of play. Int J Qual Health Care. 2016;28(1):122-128.

37. Keeney S, Hasson F, McKenna HP. A critical review of the Delphi technique as a research methodology for nursing. Int J Nurs Stud. 2001;38(2):195-200.

38. Boulkedid R, Abdoul H, Loustau M, Sibony O, Alberti C. Using and reporting the Delphi method for selecting healthcare quality indicators: a systematic review. PLoS One. 2011;6(6):e20476.
39. de Villiers MR, de Villiers PJ, Kent AP. The Delphi technique in health sciences education research. Med Teach. 2005;27(7):639-643.

40. Diamond IR, Grant RC, Feldman BM, et al. Defining consensus: a systematic review recommends methodologic criteria for reporting of Delphi studies. J Clin Epidemiol. 2014;67(4):401-409.

41. Humphrey-Murto S, Varpio L, Gonsalves C, Wood TJ. Using consensus group methods such as Delphi and Nominal Group in medical education research. Med Teach. 2017;39(1):14-19.

42. Rayens MK, Hahn EJ. Building consensus using the policy Delphi Method. Policy Polit Nurs Pract. 2000;1(4):308-315.

43. Ham W, Schoonhoven L, Schuurmans MJ, Leenen LPH. Pressure ulcers from spinal immobilization in trauma patients: a systematic review. J Trauma Acute Care Surg. 2014;76(4):1131-1141.

44. Haojun F, Jianqi S, Shike H. Retrospective, analytical study of field first aid following the Wenchuan Earthquake in China. Prehosp Disaster Med. 2011;26(2):130-134.

45. Maschmann C, Jeppesen E, Rubin MA, Barfod C. New clinical guidelines on the spinal stabilization of adult trauma patients - consensus and evidence based. Scand J Trauma Resusc Emerg Med. 2019;27(1):77.

46. Haut ERM, Kalish BT, Efron DT, et al. Spine immobilization in penetrating trauma: more harm than good? J Trauma. 2010;68(1):115-121.

47. Velopulos CGS, Shihab HM, Lottenberg L, et al. Prehospital spine immobilization/ spinal motion restriction in penetrating trauma: a practice management guideline from the Eastern Association for the Surgery of Trauma (EAST). J Trauma Acute Care Surg. 2017;84(5):736-744. 